\title{
Information skills still in demand
}

\author{
Richard Pearson
}

Employers may have to pay a high price for not taking the responsibility for training their own staff in information technology skills.

THE production and use of information technology (IT) continues to be a key factor in the growth of many economies. In the United Kingdom the market has been growing at around 15 per cent a year, and is now worth more than $£ 20,000$ million. But since the early 1980 s, there has been concern that shortages of suitably qualified staff have been constraining the development of both the IT industry and the use of IT throughout the economy.

The fastest rates of IT employment growth in the late 1980 s have been in the IT consultancy, software and services companies. In electronics, employment has been recovering after the slump of 1986-87. Among the users, growth has been variable, but has been strongest in the service sector with industry still lagging behind ${ }^{1}$. In 1988, there were more than 240,000 professional IT staff employed in the United Kingdom, an increase of about 5 per cent since 1987 , and 20 per cent since 1985. Total employment is now divided almost equally between the electronics and IT services sectors and users of IT in industry and the service sector; this represents a shift towards the user sector.

The recruitment of experienced staff continues to be the principal way in which most employers fill vacancies for professional IT staff. This, however, simply involves a reallocation of existing staff between organizations as employers chase staff with two or more years' experience of a particular technology or application. New graduates remain the main source of new entrants to the stock of professional IT staff, with demand continuing to rise throughout the $1980 \mathrm{~s}$.

In 1988, half the graduates recruited for IT work had electronics or computer studies degrees, while most of the remainder were from numerate scientific or technical disciplines. Electronics graduates went chiefly to the electronics sector Computer science graduates were recruited to all sectors although recruiters still have mixed views about the quality and relevance of such graduates. Graduates from non-IT disciplines were principally recruited for computing work, few being taken into electronics areas. Very few graduates from non-numerate disciplines take up computing work. There remains only a small demand for postgraduate qualifications in IT, principally for research work in the electronics sector and higher education.

The output of IT graduates increased rapidly in the $1980 \mathrm{~s}$, and most electronics and computer science graduates moved straight into relevant employment. The downturn in female students both applying for and entering university IT degree courses has been of particular concern, although some improvement is visible in the 1988 figures. The fall-off in interest from women has been particularly marked in computer studies; it is also reflected in the difficulties of many employers in their attempts to increase the recruitment of women to IT posts.

Recruitment difficulties continue across all professional IT occupations and sectors; the improvement shown in 1987 has not continued into 1988. Problems have been most acute for employers seeking experienced computing staff and software engineers and project managers/ leaders, and where very specific technical expertise is required or combinations of technical/commercial/personal skills. Problems in recruting new graduates seem to have been least accute in South-East England.

An increasing but still small number of employers are responding to recruitment difficulties by improving career development, retraining and deployment of staff; seeking to control wastage; increasing internal pay flexibility; reorganizing and redesigning IT work; and in some cases relocating the work to easier provincial labour markets. But progress remains slow outside the public and financial sectors where there is a history of internal staff development and retraining and salary increases remain the primary response for most employers.

Looking to the future, continued growth is expected in the IT market and in employers' needs for professional IT staff to service both business growth and the growing use of IT in new areas. Considerable uncertainty exists, however, about the rate of market growth, and the effects on employment patterns of mergers and acquisitions, European markets and competition and the contracting out of IT work.

Few employers have a developed form of manpower planning. Most plan employment and recruitment levels over no more than $12-18$ months and are therefore unable to forecast future IT employment levels with any precision.

What is clear, however, is that the labour market for professional IT staff will become increasingly compartmentalized, with the balance of supply and demand varying between sectors, locations, occupations and types of experience. There is expected to be a continuing growth in the demand for software and computing skills and applications experience, but little growth in the case of hardware skills. With the growing 'userfriendliness' and spread of IT, there will be a need for more 'hybrid' staff with both IT and application skills. Occupational boundaries will become increasingly blurred. The main growth occupations are likely to be based on communication and networks and IT consultants/business analysts because of the greater integration of IT into the business. Demand for analysts/programmers and computing is also expected to continue to grow. Overall demand is likely to grow at under 5 per cent per annum, assuming economic growth continues, representing a slowdown on recent years.

Graduates will continue to be the main source of new entrants to IT jobs and graduate intakes are expected to increase. While the supply of IT graduates is expected to continue to rise into the early $1990 \mathrm{~s}$, the increased demand from recruiters in general will put pressure on recruiters seeking to fill IT jobs from a wider range of subjects than just IT. In the mid-1990s, the output of graduates is expected to stop growing, because of the demographic downturn ${ }^{2}$. As demand is expected to continue to rise, there will be increasing competition from IT and other employers for graduates from IT and other numerate disciplines.

The outlook is for a continuation of the tight labour market for IT skilled staff. Employers will continue to face difficulties recruiting experienced professional IT staff unless they give more attention to the use of in-company resources for retraining/ conversion, to non-traditional recruitment sources and to greater flexibility in working arrangements. A start has been made by a few employers, but there is need for more innovative practices both within the IT industry and beyond in the expanding user sector.

Richard Pearson is at the Institute of Manpower Studies, Mantell Building, University of Sussex, Brighton, Sussex, BN1 9RF, UK.

1. Connor, H., Pearson, R. \& Buchan, J. The Changing IT Skills Scene: IT Manpower Monitor 1989 (IMS, Brighton, 1989).

2. Pearson, R. \& Pike, G. The Graduate Labour Market in the 1990 s (IMS, Brighton, 1989). 